\title{
LA TRAMITACIÓN DE LA REFORMA CONSTITUCIONAL MEDIANTE PROCEDIMIENTOS LEGISLATIVOS ABREVIADOS: UN PROBLEMA DE LÍMITES PROCEDIMENTALES ${ }^{1}$
}

\author{
YOLANDA GÓMEZ LUGO \\ Profesora Titular (A) de Derecho Constitucional \\ Universidad Carlos III de Madrid
}

SUMARIO

\begin{abstract}
I. El debate sobre el método y la forma de tramitación de las reformas constitucionales. II. Procedimientos legislativos abreviados y simultaneidad procedimental. III. La doctrina constitucional sobre la simultaneidad procedimental para tramitar reformas constitucionales. IV. Procedimientos abreviados como límites procedimentales a la reforma. V. Inobservancia de los límites procedimentales en la reforma constitucional: vicio in procedendo y lesión de un derecho fundamental.
\end{abstract}

\section{EL DEBATE SOBRE EL MÉTODO Y LA FORMA DE LAS REFORMAS CONSTITUCIONALES}

Aunque el debate sobre la reforma de la Constitución se ha centrado principalmente en las cuestiones de orden sustantivo, no son pocas las incertidumbres procedimentales que plantea su tramitación parlamentaria. Y si bien no faltan estudios sobre los problemas interpretativos que plantea el Título X de la Constitución, se echa en falta una reflexión sobre cómo - y cómo no- deben sustanciarse parlamentariamente las reformas constitucionales. Y en concreto, sobre la utilización simultánea de procedimientos legislativos abreviados para tramitar las proposiciones o los proyectos de reforma constitucional ${ }^{2}$.

1 Este trabajo ha sido elaborado en el marco del proyecto $\mathrm{I}+\mathrm{D}+\mathrm{I}$ «Reforma constitucional: problemas filosóficos y jurídicos» (DER2015-69217-C2-2-R), 2016-2019 del Ministerio de Economía y Competitividad.

2 Sobre esta cuestión en concreto, véase: GARCiA-Escudero MARquez, P., «La acelerada tramitación parlamentaria de la reforma del artículo 135 de la Constitución (Especial consideración de la inadmisión de 
El debate político y académico suscitado en torno al método y a la forma en que se tramitó la modificación del artículo 135 CE — tramitada simultáneamente mediante las modalidades de lectura única y urgencia- ha puesto de manifiesto las serias discrepancias existentes sobre este asunto, lo que justifica la necesidad de analizar ciertas cuestiones de orden procedimental, así como sobre las repercusiones jurídicas y políticas que este modus operandi ocasiona.

Para contextualizar correctamente esta problemática, debe tenerse presente que los artículos 167 y $168 \mathrm{CE}$ prevén sendas reservas procedimentales para la revisión de la Constitución. Ambos preceptos regulan los modos de producción de la reforma constitucional. Se trata de normas de obligada observancia para los órganos parlamentarios intervinientes en la tramitación de las proposiciones o de los proyectos de reforma constitucional. Al tratarse de una reserva procedimental fijada por la Constitución, aquéllos no podrán tramitar las propuestas reformadoras por otra vía procedimental ratione materiae. Además, técnicamente, la tramitación parlamentaria de la reforma constitucional se caracteriza por su mayor rigorismo y complejidad procedimental, que deriva del agravamiento de los trámites que conforman el iter legis y que, en el supuesto específico del artículo 168, puede hablarse de un mecanismo extraordinariamente rígido. Así lo demuestra el hecho de que en cuarenta años de vigencia de la Constitución de 1978 dicho precepto no se haya aplicado nunca, lo que viene a confirmar que el constituyente ha cumplido con su propósito. En este sentido, la doctrina ha reconocido que el artículo 168 fue concebido como una «suerte de cláusula de intangibilidad encubierta» ${ }^{3}$ con la pretensión de blindar las materias sometidas a dicho procedimiento de revisión y, muy especialmente, la institución monárquica ${ }^{4}$. Como consecuencia de ello, tras cuarenta años de vigencia constitucional puede afirmarse que dicho mecanismo procedimental ha dotado de estabilidad al sistema constitucional, pero no ha permitido actualizar los contenidos sometidos a esta reserva procedimental conforme al cauce constitucionalmente establecido.

Sin embargo, llama poderosamente la atención que, pese a esta rigidez procedimental, las dos únicas reformas constitucionales que han prosperado hasta ahora hayan sido aprobadas por el Parlamento en un plazo de tiempo realmente corto: 22 días en 1992 y 13 días en $2011^{5}$. Esta excesiva aceleración de la

enmiendas. Los límites al derecho de enmienda en la reforma constitucional)», TRC, n. ${ }^{\circ}$ 29, 2012; VILLAverde MenÉndez, I., «El control de constitucionalidad de las reformas constitucionales. ¿Un oxímoron constitucional? Comentario al ATC 9/2012», TRC, n. ${ }^{\circ}$ 30, 2012.

3 Véase, Tajadura Tejada, J., en Freixes Sanjuán, T. y Gavara de Cara, J.C. (coords.) Repensar la Constitución. Ideas para una reforma de la Constitución de 1978: reforma y comunicación dialógica, parte primera, Madrid, BOE, 2016, p. 265.

4 En esta línea se han manifestado, entre otros, PÉRez TREMPs, P., Las reformas de la Constitución hechas y no bechas, Valencia, Tirant Lo Blanch, 2018, p. 19; Punset, R., Potestades normativas y forma de gobierno, Madrid, CEPC, 2014, p. 239; TAJADURA, op.cit., p. 265.

5 En este sentido, se ha afirmado de forma acertada que esta rapidez «sorprende aún más si se contrasta con las cautelas que siempre se han alegado por los dos partidos mayoritarios a la hora de modificar el texto 
tramitación es consecuencia de la aplicación simultánea de dos procedimientos legislativos especiales junto a las normas reguladoras de la reforma previstas en el art. $167 \mathrm{CE}$, que fue el cauce seguido para modificar los artículos 13.2 y $135 \mathrm{CE}$. Y si bien ambos procesos de revisión constitucional fueron tramitados en las Cámaras de una forma similar, responden a razones y contextos diferentes que merecen ser recordados.

En la reforma aprobada en 1992 quedó clara la idea del consenso como factor clave para simultanear la tramitación de lectura única con la modalidad procedimental del artículo 167 CE. Efectivamente, la tramitación en el Congreso de los Diputados de la proposición de reforma del artículo 13.2 de la Constitución se llevó a cabo simultaneando el procedimiento de revisión constitucional del artículo $167 \mathrm{CE}$ con la técnica de la lectura única. Se trataba de un texto de artículo único que daba una nueva redacción al precepto constitucional. No puede dudarse que esta escasa extensión material facilitó los acuerdos necesarios para su aprobación, si bien la brevedad de la proposición de ley por sí sola no justifica la viabilidad de la tramitación de lectura única junto a un procedimiento legislativo especial ratione materiae ${ }^{6}$, fundamentalmente en un caso en que, pese a afectar a un texto brevísimo, no se trataba precisamente de una modificación trivial. En aquella ocasión la celeridad venía impuesta por exigencias ajenas a las Cámaras, principalmente, por la necesidad de ratificar el Tratado de Maastricht y dar cumplimiento a la declaración vinculante del Tribunal Constitucional (DTC 1/1992) reconociendo la contrariedad entre la redacción de la norma convencional y el artículo 13.2 CE. Ambos factores, externos y sobrevenidos a la institución parlamentaria, condicionaron la premura de la reforma constitucional; de ahí, que los órganos parlamentarios, Pleno y Mesa del Congreso de los Diputados, acordaran simultanear el procedimiento de reforma constitucional del artículo $167 \mathrm{CE}$, que era el procedente por razón de la materia, con los procedimientos de lectura única y de urgencia ${ }^{7}$. Sin embargo, en el Senado se siguieron únicamente las reglas de la tramitación del artículo 167 CE separándose de las modalidad legislativas abreviadas aplicadas por la Cámara baja ${ }^{8}$.

Esta aplicación simultánea de procedimientos parlamentarios dotó a las Cámaras de la flexibilidad necesaria para aprobar la reforma constitucional proyectada,

de 1978. Véase, Escudero Alday, R., «Texto y contexto de la reforma exprés de agosto de 2011», Eunomía, Revista en Cultura de la Legalidad, n. ${ }^{\circ} 2,2012$, p. 88.

6 Los procedimientos legislativos especiales constituyen modalidades de emanación de la ley sometidas a un régimen particular de tramitación y aprobación parlamentaria por razón del contenido material de la iniciativa. En estos supuestos nos encontramos ante reservas procedimentales que derivan directamente de la Constitución. A través de estos mandatos constitucionales se establece que un determinado procedimiento, distinto del iter legis común, sea de obligada observancia para las Cámaras legislativas cuando pretendan tramitar iniciativas que contengan materias tipificadas. Sobre esta materia, consúltese Gómez Lugo, Y., Los procedimientos legislativos especiales en las Cortes Generales, Madrid, Congreso de los diputados, 2008.

7 BOCG-CD, IV Legislatura, Serie B, n. ${ }^{\circ} 147-2,14$ de julio de 1992.

8 DSS, Diputación Permanente, IV Legislatura, n. ${ }^{\circ}$ 2, 21 de julio de 1992. 
que vería la luz en un periodo corto de 22 días, desde el 8 de julio de 1992, en que la proposición de ley tuvo entrada en el Congreso de los Diputados, hasta el día 30 del mismo mes que obtendría el beneplácito del Senado9. En consecuencia, las Cortes Generales ofrecieron una respuesta ágil a la altura de las exigencias demandadas por las circunstancias políticas del momento, y ello fue posible gracias a la unanimidad existente entre las fuerzas políticas parlamentarias que demostraron una clara voluntad de facilitar la adaptación del texto constitucional al Tratado de Maastricht y permitir su ratificación, a lo cual contribuyó evidentemente la ausencia de presentación de enmiendas durante la tramitación en las Cámaras.

En el supuesto de la modificación constitucional aprobada en 2011, el texto de la iniciativa fue negociado exclusivamente entre el Presidente del Gobierno y el líder de la oposición, excluyendo de dicha decisión a las restantes fuerzas parlamentarias ${ }^{10}$. Como es sabido, las razones que invocaron los proponentes de la iniciativa para acometer la revisión del artículo 135 en su exposición de motivos fueron «garantizar el principio de estabilidad presupuestaria, vinculando a todas las Administraciones Públicas en su consecución, reforzar el compromiso de España con la Unión Europea y, al mismo tiempo, garantizar la sostenibilidad económica y social». Con la pretensión política de cumplir a la mayor celeridad con dichos objetivos, la proposición fue tramitada en el Congreso conforme a los requisitos establecidos en el procedimiento ordinario del artículo 167 y, simultáneamente, en las modalidades abreviadas de lectura única y urgencia. Por el contrario, en el Senado la iniciativa de reforma siguió el cauce ordinario previsto por el artículo 167 CE y los preceptos del Reglamento del Senado que lo desarrollan.

En este contexto, la polémica suscitada trae causa de la tramitación parlamentaria seguida para la proposición de reforma del art. $135 \mathrm{CE}$ en el Congreso de los diputados, donde dicha propuesta se tramitó aplicando simultáneamente los procedimientos de urgencia y lectura única. Las críticas doctrinales sobre el método observado en esta tramitación, calificada como impropia ${ }^{11}$ para una reforma constitucional, han sido unánimes. Así, el procedimiento seguido en la modificación constitucional de 2011 ha sido considerado inadecuado ${ }^{12}$, inapropiado ${ }^{13}$,

9 Recuérdese que la proposición de reforma constitucional del art. 13.2 fue suscrita conjuntamente por todos los grupos parlamentarios respetando «el principio de consenso que presidió la elaboración constitucional».

10 Para un examen detallado de la tramitación parlamentaria de la reforma del art. $135 \mathrm{CE}$, puede consultarse GARCía-Escudero MARQUEZ, P., «La acelerada tramitación parlamentaria de la reforma del artículo 135 de la Constitución (Especial consideración de la inadmisión de enmiendas. Los límites al derecho de enmienda en la reforma constitucional)», op. cit., pp. 165 a 172. También de la misma autora, «La reforma del artículo 135: ¿son suficientes trece días para la tramitación parlamentaria de una reforma constitucional?», CDP, n. ${ }^{\circ} 38,2009$.

11 Véase, García-Escudero Marquez, P., «La acelerada tramitación parlamentaria de la reforma del artículo 135 de la Constitución...», op. cit., p. 179.

12 Bastida, F., «La reforma del artículo 135 CE», REDC, n. ${ }^{\circ} 93,2011$, p. 175. También se ha pronunciado en este sentido CARreras, F. de, REDC, n. ${ }^{\circ}$ 93, 2011, p. 190.

13 Aranda Alvarez, E., «La sustancialidad del procedimiento para la reforma constitucional», TRC, n. ${ }^{\circ} 29,2012$ 
lamentable ${ }^{14}$. Se trata de una reforma mal tramitada ${ }^{15}$ que, como afirmara el profesor Rubio, resulta «además inopinada, presentada sin estudios previos conocidos, sin discusión pública y tramitada para colmo por el procedimiento de urgencia» ${ }^{16}$. A este respecto, son muy significativas las palabras de Enoch Albertí cuando afirma que el apresuramiento y la celeridad contrastan «con los dos años que llevó la reforma de 2009 de la Grundgesetz en un sentido muy similar, en un contexto constitucional, además, en el que la reforma de la Ley Fundamental no es nada extraordinario, como prueba el hecho de que tal modificación sea la quincuagésima séptima desde su entrada en vigor en 1949» ${ }^{17}$.

Resulta evidente que la tramitación acelerada de estas dos reformas constitucionales han marcado un mal precedente para las modificaciones del texto constitucional que, tarde o temprano, deberemos emprender. Y si bien es cierto que ni la Constitución, ni los Reglamentos parlamentarios contienen una prohibición expresa que impida la tramitación parlamentaria de las propuestas de reforma constitucional conforme al método de lectura única y/o de urgencia, parece que hay suficientes razones para sostener que la utilización de estos procedimientos legislativos especiales constituye un límite procedimental implícito para las Cámaras cuando actúan como poder de reforma constitucional.

Precisamente, el objeto del presente trabajo es analizar si el Parlamento, en el ejercicio de la función reformadora de la Constitución que le confieren los artículos 167 y $168 \mathrm{CE}$, puede aplicar simultáneamente procedimientos legislativos abreviados para agilizar la tramitación de la iniciativa de reforma; o si, por el contrario, estas modalidades procedimentales actúan como límites procedimentales en la sustanciación de la reforma constitucional.

\section{PROCEDIMIENTOS LEGISLATIVOS ABREVIADOS Y SIMULTANEIDAD PROCEDIMENTAL}

Para responder al interrogante suscitado resulta ineludible tener presente el fundamento y las singularidades de los denominados procedimientos legislativos abreviados. Una adecuada comprensión de estas técnicas parlamentarias permitirá valorar la viabilidad de su aplicación simultánea junto a los procedimientos de reforma constitucional. En concreto, me centraré en las técnicas de lectura única y urgencia, ya que el artículo 75.3 CE prohíbe la aplicación del procedimiento de delegación de competencia legislativa plena en Comisión en materia de reforma constitucional.

14 Cascajo Castro, J.L., «La reforma del artículo 135 CE», REDC n. ${ }^{\circ}$ 93, 2011, p. 194.

15 CARreras, F. de: http://idpbarcelona.net/docs/blog/carreras_castellano.pdf

16 Rubio Llorente, F., «La reforma del artículo 135 CE», REDC, n. ${ }^{\circ} 93,2011$, p. 203.

17 Alberti Rovira, E., «La reforma del artículo 135 CE», REDC, n. ${ }^{\circ}$ 93, 2011, p. 167. 


\section{Fundamento de los procedimientos abreviados}

Los procedimientos legislativos abreviados, o especiales por razón del tiempo de tramitación, constituyen un conjunto de técnicas procedimentales de aplicación facultativa tendente a la aceleración de los actos parlamentarios y la tramitación legislativa. En esta línea, nuestro ordenamiento contempla diferentes modalidades, cuya singularidad reside en la capacidad para atenuar los trámites previstos para el iter legis común, pudiendo afectar bien a fases completas del procedimiento (técnica de lectura única o delegación de competencia legislativa plena en Comisión), o bien a plazos del mismo (procedimiento de urgencia) ${ }^{18}$.

Estos tres procedimientos parlamentarios se caracterizan por una serie de notas que, expuestas de forma sintética, serían las siguientes. En primer lugar, la especialidad de estas técnicas adopta la forma de atenuante procedimental, lo que significa que sobre los trámites que forman el procedimiento tipo, el iter legis común, se aplican reglas específicas conducentes a un acortamiento de la tramitación parlamentaria. Este objetivo se logra a través de la simplificación de actos, trámites o actuaciones que se desarrollan en las Cámaras; esto es, bien a través de la reducción de los plazos ordinarios, o bien mediante la restricción temporal de fases o trámites integrantes del procedimiento base. En segundo término, se trata de cauces procedimentales de aplicación potestativa para los órganos parlamentarios encargados de decidir sobre la tramitación. Por ello, ofrecen un amplio margen de maniobra a los órganos parlamentarios para seleccionarlos y aplicarlos. En unos casos, la Mesa podrá activarlos de oficio, mientras que en otros, la mayoría, únicamente podrá ponerlos en marcha a petición de determinados sujetos, generalmente el Gobierno y/o la mayoría parlamentaria. Y por último, pueden aplicarse simultáneamente con otras variedades procedimentales; es decir, se admite la «aplicación transversal» ${ }^{19}$ de diferentes procedimientos legislativos para la tramitación de una misma iniciativa legislativa, salvo cuando las normas parlamentarias excluyan expresamente esta posibilidad.

El fundamento común de estos procedimientos abreviados es lograr la celeridad de la actividad legislativa, además de combatir la lentitud propia de los procedimientos parlamentarios. Por tanto, su objetivo es simplificar los trámites y actos propios del iter legis con la pretensión de que la Cámara adopte una decisión adecuada a las circunstancias que se reclaman y en el menor tiempo posible ${ }^{20}$.

18 Para un análisis exhaustivo de estas técnicas procedimentales, consúltese Gómez Lugo, Y., Los procedimientos legislativos especiales en las Cortes Generales, op.cit. Sobre la posibilidad de creación ex novo de procedimientos abreviados a través de los Reglamentos parlamentarios, véase también Ruiz Robledo, A., «Sobre los tipos de procedimientos legislativos» en V Jornadas de Derecho Parlamentario. El Procedimiento legislativo, Madrid, Congreso de los Diputados, 1997, p. 661.

19 Véase en Garcia-Escudero Marquez, P., El procedimiento legislativo ordinario en las Cortes Generales, Madrid, CEPC, 2006, p. 110.

20 En esta línea, se ha afirmado de forma acertada que estas técnicas «tienen como objeto hacer más ágiles los procedimientos, convirtiendo a nuestras Cortes Generales en uno de los Parlamentos más rápidos de 
Al mismo tiempo a través de estos cauces procedimentales se dota de una mayor flexibilidad a la actividad de la Cámara permitiendo la adaptación a las eventualidades que reclamen la intervención legislativa. Resulta evidente que la aplicación de estas variedades transmite mayor dinamismo al Parlamento al facilitar instrumentos aptos para ofrecer una respuesta legislativa ágil a los problemas planteados, pero al mismo tiempo otorga al Ejecutivo las condiciones y mecanismos necesarios para favorecer el cumplimiento de su programa político, ya que no puede omitirse que la mayor parte de estas técnicas se activan a instancia del Gobierno y la mayoría parlamentaria que lo sustenta.

Asimismo, estas técnicas procedimentales tienen como función mejorar el rendimiento de la actividad legislativa, racionalizando el uso de los tiempos y permitiendo una mayor eficiencia en los trabajos parlamentarios. Desde esta perspectiva, resulta indudable la relevancia que el factor temporal tiene en el desarrollo del quehacer parlamentario, convirtiéndose en un aspecto esencial en aras de la funcionalidad de la institución. Cómo se regulen los tiempos por los Reglamentos parlamentarios será fundamental a estos efectos; téngase en cuenta que el establecimiento de plazos temporales demasiados rígidos podría dar lugar a decisiones parlamentarias discutidas insuficientemente y dificultar los acuerdos necesarios para la formación de la voluntad de la Cámara.

Por último, en cuanto a las razones que justifican la aplicación de estos procedimientos abreviados, éstas son variadas y de naturaleza política. La premura de la actividad legislativa puede venir motivada por la necesidad de resolver asuntos sobrevenidos, para dar curso a un texto sobre el que existe consenso político suficiente que hace innecesaria la celebración de todos los actos integrantes del iter legis, o por el deseo de cumplir el programa político del Gobierno ante el final de una legislatura y la consiguiente disolución de las Cámaras.

\section{Las singularidades de los procedimientos abreviados}

\section{a) Procedimiento de Lectura única}

La técnica de lectura única, como su propio nombre indica, conlleva la omisión de las lecturas sucesivas a las que se somete el texto durante la tramitación parlamentaria para realizar un único examen y votación que se celebrarán en el Pleno de la Cámara. De este modo, se suprimen los trámites parlamentarios que se desarrollan en sede de Comisión y Ponencia; es decir, la aplicación de este procedimiento implica que todos los actos que lo integran van a tener lugar en sede plenaria. Esta eliminación de momentos procesales durante la fase constitutiva 
conlleva lógicamente una serie de consecuencias. De una parte, en teoría supone la imposibilidad de presentación, debate y votación de enmiendas que habitualmente tiene lugar en Comisión; limitación, que se traduce concretamente en la renuncia a la propuesta de modificaciones al articulado. Y de otra, y como consecuencia de ello, se produce una restricción en el ejercicio de los derechos de participación de las minorías parlamentarias. En consecuencia, el desarrollo de la secuencia procedimental que constituye la fase central estará comprendido por dos trámites unificados en un mismo acto: de una parte, el debate de totalidad ante el Pleno de la Cámara, y de otra, la votación única a la que será sometido el texto también por el plenario, por lo que éste pasa a asumir todo el protagonismo en la gestación parlamentaria de la ley, sin intervención de otros órganos de funcionamiento como la Comisión o la Ponencia.

Se trata, pues, de una técnica procedimental tendente a facilitar respuestas rápidas del Parlamento ante propuestas legislativas que no presentan grandes dificultades para consensuar o acordar su aprobación, agilizando los trámites parlamentarios. Con ello, se produce una transformación del modelo de procedimiento legislativo que deja de someter la iniciativa a dos o tres lecturas, para canalizar el curso de la tramitación por una única lectura, esto es, un solo examen y votación del texto.

Nótese que se trata de una variedad particular del iter legis no reconocida directamente por la Constitución, sino creada por los Reglamentos parlamentarios $^{21}$. Tanto en el Congreso como en el Senado, su activación queda atribuida al Plenario, lo que puede interpretarse como una manifestación del predominio de la mayoría parlamentaria en la selección del procedimiento aplicable. El método de lectura única puede ser acordado por el Pleno del Congreso de los Diputados, a propuesta de la Mesa, oída la Junta de Portavoces (artículo 150.1 RCD). Por lo que respecta a su aplicación en el Senado, debe precisarse que esta decisión no depende de que el Congreso haya seguido esta modalidad para tramitación de la misma iniciativa; es decir, la Cámara dispone libremente la activación de esta técnica procedimental. De este modo, será también el Pleno del Senado el órgano encargado de acordar este procedimiento, siempre a propuesta de la Mesa y oída la Junta de Portavoces (artículo 129.1 RS), pero en ningún caso el órgano rector de la Cámara puede activar de oficio este procedimiento.

En cuanto a su ámbito de aplicación las normas parlamentarias que regulan este procedimiento son excesivamente ambiguas, lo que dificulta determinar la concurrencia de los elementos que justifican la tramitación parlamentaria de un proyecto o de una proposición de ley por la modalidad de lectura única y, en el caso que nos ocupa, su idoneidad para tramitar las iniciativas de reforma constitucional.

21 Tampoco en el ámbito autonómico los EEAA han reconocido esta modalidad procedimental, sino que han sido los Reglamentos de las respectivas Asambleas legislativas las que, en el ejercicio de la autonomía parlamentaria reconocida estatutariamente, han previsto el procedimiento de lectura única. 
Asimismo, y aunque dichas reglas no establecen materias vedadas, ello no significa que esta técnica no esté sometida a otro tipo de condicionantes. Por el contrario, la normativa parlamentaria supedita la utilización de este cauce procedimental a la concurrencia de supuestos tasados (STC 27/2000, FJ 6).

Los Reglamentos parlamentarios prevén que este procedimiento se acordará «cuando la naturaleza del proyecto o proposición aconsejen» o «su simplicidad de formulación lo permita» (arts. 150.1 RCD y 129.1 RS). De este modo, se desprende que los supuestos que permiten la elaboración de una ley a través de este cauce procedimental son dos: de una parte, cuando «la naturaleza» del texto lo aconseje, y de otra, cuando lo permita la «simplicidad de formulación». No puede negarse que nos encontramos ante dos fórmulas un tanto imprecisas que el propio Tribunal Constitucional ha calificado de conceptos jurídicos indeterminados (STC 129/2013, FJ 10). Esta ambigüedad ha llevado a que normalmente sea utilizado «cuando existe un consenso tal sobre el contenido de un proyecto que hace prever que el texto no sea variado en el curso de la tramitación (sea o no simple su contenido), previo acuerdo de la Junta de Portavoces» ${ }^{22}$. A mayor abundamiento, recientemente el Tribunal Constitucional ha venido a sostener que se trata de «[r]equisitos ambos definidos «mediante cláusulas o conceptos abiertos que confieren a los órganos de la Cámara un amplio margen de apreciación o de interpretación en su aplicación» (STC 215/2016, FJ 5).

El primero de los supuestos, esto es, cuando la naturaleza de un proyecto o de una proposición lo aconseje, parece referirse a textos lo suficientemente consensuados por las fuerzas políticas que hacen innecesaria la discusión y votación que tienen lugar en sede de Comisión, por lo que la tramitación se acelera suprimiendo esta fase. En cuanto al segundo elemento, la expresión simplicidad de formulación puede interpretarse referida a proyectos o proposiciones sobre cuyo contenido sólo se discute su aprobación o rechazo en bloque, sin entrar en grandes cuestiones de detalle, o bien a textos muy breves que aconsejan una agilización de los trámites. Sin duda, sería aconsejable una modificación de los Reglamentos para facilitar una redacción más clara de las circunstancias que justifican el empleo de este procedimiento y evitar una utilización inadecuada.

22 Véase Garcia-Escudero Marquez, P., «El procedimiento legislativo en las Cortes Generales: regulación, fases y tipos», TRC, n. ${ }^{\circ} 16,2005$, p. 238. Así, son tres los casos a los que se refiere la normativa vigente de los Reglamentos parlamentarios: $1^{\circ}$ ) «Para la tramitación de proyectos o proposiciones de ley muy breves y sencillos, básicamente consensuados, que sería la previsión reglamentaria», $2^{\circ}$ ) «Para la tramitación de proyectos o proposiciones sobre los que recae acuerdo unánime de tramitación particularmente acelerada por urgencia política en la promulgación de la ley. Estos proyectos o proposiciones han llegado a culminar su tramitación en una semana en cada Cámara, cuando existe una voluntad política en este sentido (por ejemplo, medidas para víctimas del terrorismo)», y $3^{\circ}$ ) «Cuando se opta por este procedimiento, o así lo impone una ley, por introducirse un elemento pactista en la elaboración del proyecto o proposición (por ejemplo, las modificaciones de la LORAFNA o los acuerdos sobre concierto y cupo económico vasco en las Comunidades Autónomas de Navarra y País Vasco). Al menos el segundo caso (previsión legal) incide negativamente sobre la soberanía legislativa de las Cámaras», ibidem. 
Como puede constatarse, el elemento determinante para la aplicación de este procedimiento no viene delimitado por el objeto material de la iniciativa, pero tampoco por la sencillez o brevedad de los textos. Y ello, porque una propuesta legislativa puede ser breve e implicar una modificación relevante del ordenamiento jurídico y, por ello, requerir una amplia discusión parlamentaria que permita alcanzar acuerdos sólidos para lograr su aprobación. Sin embargo, en resoluciones recientes el Tribunal Constitucional ha interpretado que la «simplicidad de la formulación» de la iniciativa legislativa no se refiere a la especial relevancia o trascendencia en el ordenamiento, «sino a la comprensión, sencillez e inteligibilidad de su estructura, contenido y lenguaje» (por todas, STC 139/2017, FJ 7). Igualmente carecería de sentido excluir a priori del ámbito de actuación de esta técnica procedimental todas aquellas materias sometidas a reserva procedimental, ya que ello privaría a las Cámaras de un instrumento fundamental para responder a demandas legislativas sobrevenidas. Piénsese por ejemplo en la necesidad de aprobar una serie de medidas relativas a materias reservadas a ley orgánica, demandadas socialmente y respaldadas mayoritariamente por las fuerzas políticas ante una inminente disolución de las Cámaras, ya sea natural o anticipada. En estas circunstancias la aplicación de esta técnica procedimental evitaría la caducidad de las iniciativas legislativas en curso y pendientes de resolución. Sin embargo, esto resulta aplicable a la elaboración de la ley, pero no a la tramitación de la reforma constitucional.

Realizadas estas consideraciones, y teniendo presente la práctica parlamentaria, puede afirmarse que el factor clave para la concurrencia del supuesto de hecho del procedimiento de lectura única lo constituye la existencia de consenso político suficiente para lograr el beneplácito de la Cámara. Sobre esto, quiero precisar que me refiero al consenso político como coyuntura o acuerdo generalizado amplio, no en sentido técnico como regla jurídica de la unanimidad, ya que ello sería contrario a lo dispuesto por el artículo 79 CE. Por tanto, en aquellas situaciones en que la coyuntura política permita el acuerdo necesario sobre las medidas legislativas en tramitación podrá aprobarse la propuesta en lectura única, por lo que este elemento deberá ser tenido en cuenta por la Mesa de la Cámara con carácter previo a su propuesta de tramitación.

Sin embargo, desde el ATC 9/2012 — que acoge la tesis de la simultaneidad procedimental para tramitar la reforma constitucional—, el Tribunal Constitucional viene sosteniendo que el consenso político que pueda suscitar un proyecto o una proposición de ley es algo ajeno a la concurrencia de los requisitos que permitan su tramitación por el procedimiento de urgencia (por todas, SSTC 185/2016, FJ 5 y 215/2016, FJ 5 e) ${ }^{23}$. En esta línea, considera que la especial

23 En relación con el requisito de la «simplicidad de su formulación», el Tribunal ha sostenido que este concepto jurídico indeterminado es totalmente ajeno «al consenso político que pudiera suscitar el proyecto de ley, a la repercusión pública que éste pueda tener, o a la complejidad material «intrínseca que supone 
relevancia o la trascendencia constitucional de un texto normativo "no es incompatible con su tramitación por el procedimiento en lectura única,... al que no le está vedada materia alguna, incluida la reforma constitucional (STC 238/2012, FJ 4, que reproduce la doctrina del ATC 9/2012, de 13 de enero)» (STC 185/2016, FJ 5 c).

\section{b) Procedimiento de urgencia}

Por lo que respecta al procedimiento de urgencia, la Constitución no regula esta abreviación de la tramitación parlamentaria como un procedimiento legislativo aplicable por igual en ambas Cámaras, sino que únicamente incorpora dos breves referencias en su articulado, dirigidas a cada una de las Cámaras por separado. De una parte, en el artículo 86.3, y al hilo de la intervención parlamentaria en la tramitación del decreto-ley. Y de otra, prevé la simplificación procedimental aplicable en la Cámara Alta al disponer que «el plazo de dos meses de que el Senado dispone para vetar o enmendar el proyecto se reducirá al de veinte días naturales en los proyectos declarados urgentes por el Gobierno o por el Congreso de los Diputados» (art. 90.3). Este modo de abordar la regulación de la declaración de urgencia, ha suscitado un debate doctrinal en torno a la consideración de esta figura como un procedimiento legislativo especial autónomo, o bien como una mera regla de funcionamiento de las Cámaras ${ }^{24}$. No obstante, se trata de un procedimiento con apoyatura constitucional cuyo reconocimiento deriva de los artículos 90.3 y $86.3 \mathrm{CE}^{25}$, que determinan los efectos que la declaración de urgencia produce en la tramitación legislativa.

La principal característica de esta técnica en la Cámara baja consiste en la reducción a la mitad de los plazos establecidos para el procedimiento legislativo ordinario (art. 94 RCD), manteniendo todas las fases previstas para éste. Ello implica una disminución del tiempo destinado al examen de la iniciativa, a la presentación y votación de las enmiendas, así como una reducción de la duración de las intervenciones, discusión y votación del texto definitivo; limitaciones, que afectan directamente a los derechos de los parlamentarios en la tramitación del iter legis y que en el caso del Senado producirá unos efectos más drásticos dada la rigidez de los plazos fijados. Efectivamente, en el caso del Senado las previsiones

la función administrativa de aplicación del ordenamiento jurídico, que no se ha trasladado en modo alguno a la formulación de la ley.» (STC 129/2013, FJ 10).

$24 \mathrm{La}$ tesis de la declaración de urgencia como mera norma de funcionamiento de las Cámaras fue sostenida por el TC en la STC 234/2000, y sigue manteniéndola en resoluciones más recientes como las SSTC 143/2016 ó 215/2016. Para un análisis detallado de este debate, véase GómEz Lugo, Y., «La urgencia del iter legis: una técnica procedimental de agilización procedimental a disposición del Gobierno», $R D P$, n. $^{\circ} 71-72,2008$.

25 Véase en Garcia-Escudero Marquez, Piedad, «El procedimiento legislativo en las Cortes Generales. Regulación, fases y tipos», TRC, n. ${ }^{\circ} 16,2005$, p. 236. 
constitucionales y parlamentarias establecen que la duración de la tramitación quedará reducida a veinte días naturales, frente a los dos meses que dura en el procedimiento ordinario, como se desprende del artículo 90.2 de la Constitución (art. 133 RS). Además, debe tenerse en cuenta que en ambas Cámaras el acortamiento de la tramitación que implica el procedimiento de urgencia es perfectamente compatible con la aplicación de la regla general de ampliación o reducción de tiempos ${ }^{26}$.

La decisión sobre la tramitación conforme al procedimiento de urgencia puede adoptarse tanto a petición de determinados órganos parlamentarios, como por iniciativa de sujetos ajenos a las Cámaras. El Reglamento del Congreso atribuye esta capacidad a órganos exclusivamente parlamentarios, al señalar como sujeto legitimado para instar la activación de esta modalidad a la Mesa de la Cámara, a propuesta del Gobierno, dos Grupos parlamentarios o una quinta parte de los diputados (art. 93.1 RCD). La normativa del Reglamento del Senado admite no sólo el origen parlamentario de la decisión sobre la urgencia, sino también la activación procedimental mediante la declaración procedente de órganos ajenos a la Cámara Alta. Efectivamente, en este supuesto son dos grupos los sujetos legitimados para poner en marcha este cauce procedimental. De una parte, se atribuye a la Mesa del Senado la potestad de activarlo de oficio, o bien a propuesta de un Grupo parlamentario o veinticinco senadores (art. 133.2 RS). Y de otra, se reconoce al Gobierno y Congreso de los Diputados la capacidad para declarar la urgencia; instancias, ajenas a la Cámara en la que se tramita el texto.

Tanto la normativa constitucional como las previsiones de los Reglamentos parlamentarios supeditan la aplicación de esta modalidad procedimental a la declaración de urgencia, por lo que ésta se presenta como el acto de naturaleza política que impulsa la activación de la especialidad y cuya adopción corresponde a los sujetos legitimados por las fuentes parlamentarias. Desde este modo, la declaración se convierte en el presupuesto habilitante de este mecanismo procedimental, y cuya concurrencia deberá verificar la Mesa de la Cámara antes de iniciar los trámites propios del procedimiento de urgencia. Lo que parece indudable es que esta «declaración de urgencia» sólo puede acordarse ante circunstancias que requieren de cierta celeridad en su resolución legislativa, o situaciones que necesitan una actuación legislativa del Parlamento en un plazo inferior a cualquiera de los que ofrece el resto de modalidades procedimentales, incluyendo tanto el iter legis ordinario, como los restantes procedimientos abreviados. De este modo, quedaría justificada la idoneidad de este cauce procedimental, cuando se requiriera la adopción de medidas normativas de forma inmediata por parte del

26 Efectivamente, la aplicación de esta atenuación procedimental es perfectamente compatible con la regla general de reducción de tiempos prevista por los Reglamentos parlamentarios, como se desprende de los artículos 94 RCD, al prever que «sin perjuicio de lo establecido en el artículo 91 del presente Reglamento, los plazos tendrán una duración de la mitad de los establecidos con carácter ordinario»; y del 135.6 RS al disponer que «La Mesa podrá acordar modificaciones en los plazos cuando así lo aconsejen las circunstancias». 
Parlamento por excepcionales circunstancias políticas que no pudieran esperar al normal desarrollo legislativo, que habitualmente se caracteriza por su lentitud. Parece deducirse que la voluntad de declarar la urgencia, como acto que activa el mecanismo procedimental, constituye en realidad una valoración estrictamente política por parte de los sujetos legitimados por el ordenamiento a tal efecto.

\section{La aplicación simultánea de procedimientos parlamentarios}

Resulta indudable que la complejidad propia de la vida política y parlamentaria condiciona el uso de los procedimientos parlamentarios, llegando incluso a forzar la aplicación sincrónica de diferentes modalidades legislativas especiales. La praxis parlamentaria pone de manifiesto cómo la simultaneidad procedimental constituye una práctica habitual en las Cámaras. Precisamente, esta realidad obliga a cuestionarse la idoneidad de esta técnica desde la perspectiva de los procedimientos parlamentarios de reforma constitucional.

Los supuestos de aplicación transversal ${ }^{27}$ de procedimientos legislativos especiales son múltiples en la actividad de las Cámaras. Algunos resultan admisibles conforme a la legalidad parlamentaria, sin embargo otros suscitan ciertas dudas de constitucionalidad, como es el caso que nos ocupa.

La constitucionalización de determinadas reservas procedimentales permite reconocer cierta preferencia en la aplicación de los procedimientos legislativos especiales ratione materiae frente al iter legis común y a los especiales abreviados. El carácter obligatorio o imperativo de la primera modalidad impone a las Cámaras un modo concreto de actuación; ahora bien, esta aparente preferencia se difumina desde el momento en que se admite la posibilidad de simultanearlos con las técnicas legislativas abreviadas. La aplicación de procedimientos ratione materiae no impide que los órganos parlamentarios puedan disponer el uso concurrente de especificidades de carácter temporal, a excepción de las exclusiones previstas constitucionalmente, como las establecidas en el art. 75.3 CE.

Asimismo, debe advertirse que los procedimientos abreviados son un cauce alternativo al iter legis ordinario cuando las circunstancias políticas requieren de una rápida intervención legislativa por parte del Parlamento. Ahora bien, en materia de revisión constitucional, su aplicación — en caso de admitirse - no tendrá carácter alternativo, sino necesariamente concurrente; y ello, como consecuencia de las reservas procedimentales que derivan de los artículos 167 y 168 CE.

Por lo que respecta a la técnica legislativa de lectura única, las normas parlamentarias permiten su utilización simultánea o transversal tanto con

27 Entre los términos utilizados por la doctrina para referirse a esta posibilidad de combinación de varios procedimientos legislativos, P. García-Escudero emplea la expresión «aplicación transversal». Consúltese GARCiA-Escudero Marquez, Piedad, El procedimiento legislativo ordinario en las Cortes Generales, op. cit., p. 110. 
procedimientos legislativos especiales por razón de la materia, como con las otras dos modalidades legislativas abreviadas. Sin embargo, en el presente supuesto y pese a la ausencia de límites materiales para su aplicación, creo que sería conveniente que los Reglamentos parlamentarios exceptuasen la aplicación del método de lectura única a algunas materias sometidas a procedimientos particularizados por razón material, y en concreto, a la reforma constitucional. En principio, podría argüirse que la mayor notoriedad de las materias sometidas a dichas reservas procedimentales desaconseja su simultaneidad con la técnica de lectura única. En cuanto al procedimiento de urgencia, los Reglamentos parlamentarios permiten su aplicación simultánea junto a otras modalidades procedimentales abreviadas o por razón material. Este dato queda corroborado por la práctica parlamentaria que refleja el uso coetáneo de esta técnica junto a la variante de Comisión con competencia legislativa plena y el método de lectura única. En cuanto a la simultaneidad de la urgencia con los procedimientos especiales por razón material, en principio, no suscita problema alguno habida cuenta de la ausencia de límites materiales excluidos del ámbito de su aplicación.

Por tanto, según las normas parlamentarias ni la modalidad de lectura única, ni el procedimiento de urgencia tienen previstos condicionantes materiales para su aplicación, por lo que estas formas de tramitación son de aplicación genérica a todos los proyectos o proposiciones de ley independientemente de su contenido. Sin embargo, existen dudas razonables sobre su idoneidad para tramitar proyectos o proposiciones de reforma constitucional.

\section{LA DOCTRINA CONSTITUCIONAL SOBRE LA SIMULTANEIDAD PROCEDIMENTAL PARA TRAMITAR REFORMAS CONSTITUCIONALES}

En el ATC 9/2012 el Tribunal Constitucional tuvo la ocasión de enfrentarse, por primera vez, al tema del control jurisdiccional de las reformas constitucionales por inadecuación procedimental. En dicho auto se pronunció sobre alguna de las incertidumbres que plantea la tramitación parlamentaria de las propuestas de reforma, y en concreto, sobre la sustanciación de la reforma de la Constitución mediante procedimientos legislativos abreviados.

Con motivo de la tramitación parlamentaria de la modificación constitucional de art. 135 CE, varios diputados del Grupo Parlamentario Esquerra Republicana-Izquierda Unida-Iniciativa Per Catalunya Verds interpusieron recurso de amparo parlamentario contra varios acuerdos de la Mesa y del Pleno del Congreso de los Diputados sobre la tramitación de la proposición de reforma por vulneración del artículo 23 CE. A juicio de los parlamentarios recurrentes los actos internos de las Cámaras lesionaban su ius in officium, en su vertiente del derecho a tramitar las iniciativas por el procedimiento adecuado. El recurso impugnó varios actos parlamentarios sin valor de ley por la vía del artículo 42 LOTC por una 
doble inadecuación de los procedimientos legislativos observados para tramitar la proposición de reforma constitucional.

El primer motivo de inadecuación procedimental deriva de la decisión de tramitar la proposición de reforma constitucional por el procedimiento ordinario del art. 167, en lugar de hacerlo por la vía extraordinaria del art. 168. En realidad, esta primera queja trae causa de la discrepancia con la calificación otorgada por la Mesa a la propuesta de reforma, con la consiguiente disconformidad con la decisión sobre el modo de su tramitación parlamentaria. A juicio de los recurrentes la reforma propuesta suponía una modificación encubierta del Título preliminar de la Constitución — en concreto, del art. 1.1 CE_-, por lo que solicitaron la nulidad de los actos impugnados y la retrotracción de la tramitación al momento de publicación de la iniciativa, al objeto de reconducir su tramitación conforme al procedimiento agravado del art. 168. La decisión parlamentaria de seguir este último cauce procedimental afectaba a los derechos de participación política de los diputados, y de los ciudadanos, al eliminar las preceptivas convocaría electoral y del referéndum previstos por el art. 168.

Por otra parte, y con carácter subsidiario, alegaron una segunda inadecuación procedimental al cuestionar la idoneidad de los procedimientos legislativos observados (lectura única y urgencia) para la tramitación parlamentaria de la reforma constitucional; y por ello, solicitaron, subsidiariamente, la sustanciación de la reforma controvertida por el procedimiento ordinario del art. 167 sin declaración de urgencia y sin aplicar el método de lectura única. De forma resumida, las razones esgrimidas para sustentar sus pretensiones fueron principalmente: reducción de las facultades de participación en sede de Comisión como consecuencia de la técnica procedimental aplicada a la reforma del art. 135; falta de encaje de la reforma constitucional en los supuestos previstos para la aplicación de la modalidad de lectura única; y ausencia de motivación de los órganos parlamentarios al decidir sobre la tramitación por los procedimientos aplicados.

Sin duda, una de las cuestiones más sorprendentes de este pronunciamiento es que, pese a tratarse de un Auto de inadmisión a trámite de un recurso de amparo, el Tribunal efectúa un juicio de fondo sobre las cuestiones suscitadas en la demanda. Precisamente el tipo de resolución emitida por el Alto Tribunal en el presente caso ha sido un aspecto que ha producido cierto asombro y ha recibido justificadas críticas doctrinales ${ }^{28}$. En su voto particular, el Magistrado Pablo Pérez Tremps criticó el fallo de inadmisión del Auto al no alcanzar el razonamiento sobre la lesión de la norma fundamental, que debiera haberse hecho mediante Sentencia, y no de forma liminar. A su juicio, «una cuestión técnicamente compleja, novedosa, de evidente interés constitucional, suscitada por parlamentarios representantes del pueblo español no debería haberse inadmitido a

28 En este sentido se ha pronunciado Villaverde Menéndez, I., op. cit., pp. 485 y ss. 
trámite sino que debería haber sido objeto de un pronunciamiento más reposado y tras un análisis procesalmente completo de las cuestiones planteadas.».

Creo que el Tribunal debería haber admitido a trámite el recurso de amparo, ya que el asunto suscitado presentaba especial trascendencia constitucional por dos razones. Por un lado, porque planteaba un problema o faceta de un derecho fundamental sobre el que no existe doctrina constitucional (STC 155/2009, FJ 2 a): enjuiciar la función de calificación y admisión a trámite de la Mesa del Congreso en relación con las propuestas de reforma constitucional. Y por otro, porque el asunto suscitado trascendía del caso concreto al plantear una cuestión jurídica de relevante y general repercusión social (STC 155/2009, FJ 2 g); en concreto, planteaba diversos problemas relativos a la tramitación parlamentaria de las reformas constitucionales, una cuestión con clara repercusión general y sobre la cual el Tribunal no se había pronunciado antes.

Respecto al primer motivo de inadecuación procedimental esgrimido, esto es, sobre la discrepancia suscitada por los recurrentes en torno a la calificación de la proposición de reforma constitucional controvertida dentro de los supuestos objeto del procedimiento previsto en el artículo 167, el Tribunal se limitó a acoger la interpretación literal del artículo 168 que sostuvo en la DTC 1/1992, en virtud de la cual la Constitución «establece de manera precisa la finalidad de las dos vías de reforma que prevé, en función de los objetos sobre los que se puede proyectar» (FJ 2). Sobre ello, considera que acceder a la pretensión de los recurrentes de retrotraer la tramitación al momento de la publicación de la iniciativa al objeto de que se tramitase por la vía del art. 168 implicaría «el riesgo de dejar a la discreción del órgano rector de la Cámara la determinación del procedimiento de reforma constitucional». Esto no es totalmente cierto y debería haberse matizado a la luz de la doctrina constitucional, especialmente del ATC 85/2006. De una parte, el diputado tiene derecho a tramitar las iniciativas por el procedimiento adecuado conforme a las normas constitucionales y reglamentarias, y de darse un error o discrepancia en la calificación de la iniciativa puede solicitar la reconsideración de la calificación otorgada y solicitar la reconducción del procedimiento en función de la recalificación de la propuesta. A este respecto, para resolver los diferentes supuestos de recalificación de las iniciativas se ha propuesto, de forma muy acertada, aplicar por analogía la regulación y la práctica existentes respecto de las leyes orgánicas ${ }^{29}$. Por otro lado, el Tribunal olvida aquí que la aplicación del procedimiento agravado del artículo 168 está sometida a un requisito material, cuya concurrencia debe verificar la Mesa en los trámites de calificación y decisión sobre la tramitación.

Por lo que respecta a la segunda queja relativa a la simultaneidad de la reforma del art. 135 junto al procedimiento de lectura única, el Tribunal realiza,

29 Sobre las diferentes posibilidades de solución, véase GARCíA-Escudero MARQuEz, P., «El procedimiento agravado de la reforma de la Constitución de 1978», RDP, n. ${ }^{\circ}$ 71-72, 2008, pp. 181-182. 
a mi juicio, un examen incompleto de este asunto y acude a un argumento meramente formalista limitándose a confirmar la inexistencia de límites materiales para la adopción de dicho procedimiento ${ }^{30}$. En este sentido, sostuvo que «[n]i de la lectura del texto constitucional en su conjunto, ni de modo especial del título $\mathrm{X}$ dedicado por la propia Constitución a su posible reforma, ni del art. 146 del Reglamento del Congreso de los Diputados (RCD) se advierte que la aprobación de la reforma constitucional haya quedado excluida del procedimiento de lectura única» (ATC 9/2012, FJ 3) 31 . Aunque esta afirmación es cierta, no creo que el Tribunal haya enfocado correctamente la cuestión suscitada, ya que presupone que el elemento material es el único criterio determinante para la aplicación del procedimiento de lectura única. Por el contrario, y como se expuso anteriormente, la viabilidad de esta técnica procedimental no viene delimitada por el objeto material de la iniciativa, sino por una serie de supuestos, ambiguos, pero tasados en los Reglamentos parlamentarios que, en ningún momento, el Tribunal tiene en cuenta ${ }^{32}$.

Por otro lado, el Tribunal considera que «no es un dato menor que la única especialidad procedimental vetada por la Norma Fundamental, en relación con la reforma constitucional es la eventual atribución de la aprobación de la misma a una comisión legislativa permanente (art. 75.3 CE)». Sin embargo, sobre este particular el Tribunal olvida que el procedimiento de lectura única no existía en 1978, ya que fue creado con la aprobación de los Reglamentos parlamentarios en 1982, y en consecuencia, esta cuestión debe ser analizada tomando como parámetro también las disposiciones previstas en los mismos.

En cuanto al cuestionamiento referente a la sustanciación de la reforma constitucional por la vía de urgencia, el Tribunal se limita a negar que la tramitación urgente haya impedido a los recurrentes las facultades que les corresponden en el seno del procedimiento legislativo (ATC 9/2012, FJ 4). A este respecto, trae a colación su doctrina sobre la declaración de urgencia en relación con el procedimiento legislativo (STC 234/2000), si bien creo que la misma no puede extrapolarse, sin mayores precisiones, al ámbito de la reforma constitucional. Aun tratándose del procedimiento abreviado de aplicación más genérica por ausencia de condicionantes de ningún tipo — salvo la propia declaración de

30 En este sentido, no le faltan razones a Villaverde Menéndez cuando afirma que el Auto incurre en cierto «formalismo parlamentario enervante». Véase, Villaverde MenÉndeZ, I., op. cit., p. 487.

31 El TC volvió a reiterar este argumento en la STC 238/2012, FJ 4.‥

32 En el mismo sentido se pronuncia el Magistrado E. Gay Montalvo, al sostener que la decisión mayoritaria debería haber analizado si la votación del Pleno de la Cámara que acuerda adoptar el procedimiento de lectura única observa o no el mandato normativo contenido en el art. 150 RCD. Igualmente, considera que la proposición de ley de reforma de la Constitución «tenía tantas complicaciones que no puede decirse, a primera vista, que tuviese una formulación simple»; y tratándose de una reforma de un texto constitucional que «se gestó como fruto de un delicado consenso pareciera que también hubiera motivos para entender que su naturaleza requería de una tramitación tal que facilitara la participación más plural posible, con la cual no se compadece el procedimiento de lectura única.». 
urgencia, que actúa como presupuesto previo-, creo que no puede abordarse esta cuestión sin tener en cuenta otros elementos como el propio fundamento y rasgos de los procedimientos parlamentarios de revisión constitucional. Da la sensación de que el Tribunal está equiparando los procedimientos de reforma constitucional a los procedimientos parlamentarios legislativos ${ }^{33}$, sin atender a las diferencias existente entre ambos y corriendo el riesgo de desnaturalizar la propia configuración jurídica de los cauces previstos para proceder a la modificación de la Constitución.

De este modo, y sin mayores precisiones de fondo, el Tribunal Constitucional en el ATC 9/2012 acoge la tesis de la simultaneidad procedimental para tramitar la reforma de la Constitución, en virtud de la cual resulta admisible la aplicación transversal de los procedimientos parlamentarios de reforma constitucional y las modalidades abreviadas de lectura única y urgencia; tesis, que ha sido reiterada en varias resoluciones posteriores (SSTC 238/2012, FJ 4; 185/2016, y $215 / 2016$, FJ 5). Sin embargo, el pronunciamiento adolece de algunas imprecisiones. Por ejemplo, cuando afirma que del texto constitucional no se desprende «que la aprobación de la reforma constitucional haya quedado excluida del procedimiento de lectura única», lo hace de forma genérica sin especificar si se refiere solo a la vía ordinaria del art. 167, o si por el contrario, esta doctrina sería extensible a la intervención de las Cámaras de segunda legislatura del procedimiento agravado de reforma. Tampoco las sentencias posteriores, en las que reproduce la doctrina de la simultaneidad procedimental de la reforma constitucional, resuelven este interrogante.

A mi juicio, la resolución de la demanda amparo en el presente caso requería un correcto enfoque de las cuestiones de fondo suscitadas. De este modo, se echa en falta que el Tribunal no hubiera analizado en profundidad los Acuerdos de la Mesa del Congreso sobre calificación, admisión y decisión de la tramitación de la propuesta de reforma constitucional controvertida al objeto de comprobar si habían vulnerado el derecho de los recurrentes a acceder en condiciones de igualdad a las funciones y cargos públicos con los requisitos que señalen las Leyes, en su vertiente del derecho a tramitar las iniciativas por el procedimiento adecuado (art. 23.2 CE). Ello hubiera requerido traer a colación la consolidada doctrina constitucional sobre dos cuestiones (a) el mencionado derecho fundamental en conexión con (b) la potestad de las Mesas de las Cámaras de calificar y admitir o no a trámite las iniciativas parlamentarias y su incidencia sobre el ius in officium del cargo parlamentario. Obviamente, ello hubiera requerido la admisión a trámite del recurso de amparo y su resolución mediante sentencia.

33 En esta línea, el Magistrado L.I. Ortega Álvarez formula un voto particular en el que discrepa de la decisión mayoritaria, precisamente, que el Tribunal no estableciera distinción entre «los procedimientos parlamentarios legislativos, en los que las Cortes como institución y los representantes del pueblo actúan como órganos y poderes constituidos y los procedimientos parlamentarios de reforma constitucional, en los que actúan como poder constituyente». 


\section{PROCEDIMIENTOS ABREVIADOS COMO LÍMITES PROCEDIMENTALES A LA REFORMA}

Aunque la Constitución española, a diferencia de otros textos constitucionales como el italiano o el alemán, «no excluye de la posibilidad de reforma [sic] ninguno de sus preceptos ni somete el poder de revisión constitucional a más límites expresos que los estrictamente formales y de procedimiento» (STC 48/2003, FJ 7), es posible deducir algunos límites procedimentales derivados de sus preceptos y de los Reglamentos parlamentarios.

En este sentido, la actuación de las Cámaras para tramitar la modificación de la Constitución no queda sometida únicamente al conjunto de requisitos exigidos a tal efecto por los artículos 167 y 168 CE, que actúan como límites formales o de procedimiento. Junto a éstos, y haciendo una interpretación sistemática de las normas constitucionales y parlamentarias que regulan el modo de producción legislativa, pueden deducirse otras limitaciones que condicionan la tramitación parlamentaria de la revisión de la Constitución ${ }^{34}$.

\section{Límites procedimentales explícitos}

De este modo, junto a los preceptos constitucionales del Título X que regulan los modos de producción de la reforma constitucional, pueden señalarse otros condicionantes de forma o de procedimiento que derivan directamente de la Constitución y entre los que cabe señalar los fijados en los artículos 166 y 75.3 $\mathrm{CE}^{35}$.

El primero de los límites procedimentales explícitos vendría determinado por lo dispuesto en los artículos 167 y 168 CE. Así, la previsión constitucional de cauces procedimentales particularizados por los que debe discurrir el poder reformador constituye en sí un límite procedimental en un doble sentido. Teniendo en cuenta que el art. 168 somete una serie de materias a la reserva procedimental prevista en dicha disposición constitucional, este mecanismo extraordinario de reforma actúa como un límite procedimental frente a las materias no reservadas a dicho cauce. Por otro, y como consecuencia de ello, el procedimiento ordinario del artículo 167 queda vedado para la modificación de las materias sometidas a la técnica más agravada prevista en el art. 168.

34 Nótese que las normas del iter legis común son de aplicación supletoria para todo aquello no previsto por el régimen jurídico de los procedimientos legislativos especiales y también de los procedimientos parlamentarios de reforma constitucional. En este sentido, el artículo $146 \mathrm{RCD}$ establece que «[1]os proyectos y proposiciones de reforma constitucional a que se refieren los artículos 166 y 167 de la Constitución se tramitarán conforme a las normas establecidas en este Reglamento para los proyectos y proposiciones de ley...».

35 Dejo al margen el límite circunstancial previsto en el artículo169 CE que prohíbe iniciar los procedimientos de reforma constitucional en las situaciones especificadas en el mismo. 
En segundo término, el artículo 166 CE remite a los párrafos primero y segundo del artículo $87 \mathrm{CE}$, lo que excluye la posibilidad de iniciar cualquier revisión de la Constitución por iniciativa popular (art. 87.3 CE). En este supuesto, nos encontramos con una disposición constitucional que articula un límite formal o de procedimiento que afecta a la fase inicial del iter y que excluye el ejercicio de la iniciativa popular en materia de reforma constitucional.

Y por último, el artículo 75.3 CE exceptúa la delegación de competencia legislativa a favor de las comisiones parlamentarias para la sustanciación de las reformas constitucionales, por lo que en este caso se trata de una limitación expresa que restringe la actuación del Parlamento cuando actúa en el ejercicio de las competencias atribuidas por los artículos 167 y 168 CE. En este supuesto, y si bien el precepto constitucional dispone un límite material para la aplicación del procedimiento abreviado previsto por el art. 75.2, desde la óptica del poder de reforma constitucional actúa como un auténtico límite procedimental, de tal suerte que impide a las Cámaras agilizar la tramitación parlamentaria aplicando simultáneamente la modalidad fijada por el artículo 75.2 CE junto a los procedimientos de los artículos 167 y 168 CE. No obstante, y aunque el constituyente no hubiera previsto explícitamente esta prohibición, la aplicación de este procedimiento abreviado seguiría estando vedada para la sustanciación de la reforma constitucional porque el objeto de la delegación es la aprobación de «proyectos o proposiciones de ley», no de reformas constitucionales. Además, lo que se delega a través de esta técnica procedimental es el ejercicio de la función legislativa del artículo 66.2 CE, no de la función de reforma de la Constitución conforme a las previsiones del Título X.

Esta tesis se ha visto confirmada por el Tribunal Constitucional al reconocer que «la única especialidad procedimental vetada por la Norma Fundamental, en relación con la reforma constitucional, es la eventual atribución de la aprobación de la misma a una comisión legislativa permanente (art. 75.3 CE)» (ATC 9/2012, FJ 3). Si bien, debe advertirse un dato que el Alto Tribunal parece omitir en este pronunciamiento, y es que los procedimientos abreviados de lectura única y de urgencia no fueron creados por el constituyente, sino por las propias Cámaras. Efectivamente, como se expuso con anterioridad, los Reglamentos parlamentarios de 1982 crearon ambas modalidades en el ejercicio de su autonomía reglamentaria $\mathrm{y}$ de funcionamiento interno que tienen reconocida constitucionalmente, si bien en el caso del procedimiento de urgencia contaba con una base constitucional.

\section{Límites procedimentales implícitos: la tramitación por lectura única y procedimiento de urgencia}

En este orden de consideraciones, cabe cuestionarse si existen límites procedimentales no contemplados expresamente por la Constitución, pero que puedan derivarse implícitamente de otros preceptos constitucionales o de los 
Reglamentos parlamentarios. En este caso estaríamos hablando de límites procedimentales o de procedimiento de carácter implícito. A este respecto, resulta necesario realizar una precisión conceptual para aclarar que no me estoy refiriendo a la expresión o categoría de «límites implícitos formales» utilizada por Pedro de Vega, siguiendo la tesis de Merkl y Ross, para aludir al carácter irreformable de las normas que regulan el poder de reforma constitucional y que, desde esta perspectiva, constituirían auténticas clausulas de intangibilidad ${ }^{36}$. Me refiero a limites procedimentales implícitos entendidos como condicionantes en sentido amplio, como predeterminaciones procedimentales y no como mera prohibición o impedimento ${ }^{37}$. Desde esta perspectiva, este tipo de límites estaría constituido por el conjunto de condicionantes de forma y de procedimiento que se derivan de la previsión normativa de procedimientos legislativos abreviados, y que resultan incompatibles con los presupuestos propios de la reforma constitucional. Ya se ha señalado el límite expreso que deriva del art. 75.3 CE en relación. Sin embargo, se plantean mayores dificultades interpretativas en el caso del resto de modalidades legislativas abreviadas que no fueron creadas directamente por la Constitución, como el método de lectura única y el procedimiento de urgencia. En ambos supuestos, ni la Constitución ni los Reglamentos parlamentarios prohíben su aplicación transversal o simultánea junto a los procedimientos parlamentarios de reforma constitucional. No obstante, hay razones que justifican su no aplicación simultánea.

A los efectos de una mayor claridad expositiva, los motivos que podrían esgrimirse para sustentar la inadecuación de tramitar las reformas constitucionales aplicando simultáneamente los procedimientos legislativos de urgencia y de lectura única pueden sintetizarse del siguiente modo: (a) Los procedimientos de reforma constitucional y los abreviados responden a fundamentos diferentes y contrapuestos (b) Las técnicas abreviadas, y especialmente la de lectura única, limitan el debate parlamentario y afectan al derecho de enmienda; (c) Existen dificultades para subsumir la reforma constitucional entre los supuestos tasados previstos para la adopción del procedimiento de lectura única; (d) La aplicación de la modalidad de lectura única para tramitar la reforma suprimiría la función técnica y política de la Comisión parlamentaria.

El primer inconveniente para admitir la aplicación simultánea de los mecanismos de reforma constitucional junto a cualquiera de los procedimientos

36 Sobre la noción de límites implícitos formales y la irreformabilidad de las normas de procedimiento, consúltese DE VEGA GARCíA, P., La reforma constitucional y la problemática del poder constituyente, Madrid, Tecnos, 1988 (1. ${ }^{a}$ reimpresión), p. 277 y ss.

37 Para una visión de los límites como impedimentos, puede verse en Belda Pérez-Pedrero, E., «Los límites a la reforma constitucional ante propuestas más propias de una revolución», TRC, n. ${ }^{\circ}$ 29, 2012. Para este autor, el artículo 169 no sería límite temporal o circunstancial porque no «impide» la reforma, sino solo su comienzo (p. 266). Tampoco considera límites las condiciones exigidas en los arts. 167 y 168, puesto que «su finalidad no es delimitar ni dificultar la reforma, sino garantizar que el proceso de cambio se efectúa con sometimiento a la voluntad del constituyente». 
legislativos abreviados deriva de los diferentes presupuestos sobre los que se asientan estas modalidades procedimentales. Como se expuso anteriormente, estas técnicas responden a la finalidad de combatir la lentitud propia de la actividad del Parlamento y acelerar la tramitación legislativa simplificando los actos del iter legis común. Desde esta óptica, atienden a razones de economía procesal con la pretensión de economizar los tiempos y las fases del iter para facilitar una respuesta legislativa rápida. Sin embargo, la revisión de la Constitución está sometida a una reserva procedimental, que deriva de los arts. 167 y $168 \mathrm{CE}$ y que se caracteriza por el reforzamiento y agravamiento de los actos y trámites parlamentarios. De este modo, el fundamento de los procedimientos previstos para tramitar la reforma es garantizar la supremacía constitucional y permitir la adaptación de la Constitución a los cambios sociales y políticos. En mi opinión, los procedimientos parlamentarios de reforma constitucional y los legislativos abreviados responden a fundamentos no solo distintos, sino también incompatibles. Procedimentalmente, son técnicas contrapuestas. Mientras que las normas que regulan el ejercicio del poder reformador se caracterizan por su especial rigidez y complejidad técnica, los procedimientos abreviados se definen por la simplificación procedimental.

La segunda dificultad observada deriva de las propias especialidades procedimentales que caracterizan al método de lectura única, en el que la iniciativa se somete a un debate de totalidad en el Pleno de la Cámara (arts. 151.2 RCD y 129.2 RS), y seguidamente a una única votación. Como consecuencia de ello, quedan excluidas las enmiendas al articulado, es decir, aquellas que tienen un sentido claramente técnico y formal. Sobre ello, debe mencionarse que en el Congreso «se admite en la práctica la presentación de enmiendas al proyecto, aunque la regulación contenido en el artículo 150 podría no avalar esta situación» ${ }^{38}$. Por lo que respecta a la aplicación de este procedimiento en la Cámara Alta, el propio Reglamento prevé explícitamente la limitación del derecho de enmienda al establecer que «podrán presentarse únicamente propuestas de veto» (art. 129.3 RS), lo que ha sido criticado por la doctrina, ya que efectivamente restringe las facultades legislativas de los parlamentarios y, en concreto, la posibilidad de presentar enmiendas, con su consiguiente discusión y votación ${ }^{39}$. Ante esta situación la minoría parlamentaria ve disminuidas considerablemente sus facultades de enmendar el texto propuesto; derecho, a través del cual interviene activamente en la tramitación del procedimiento legislativo, bien sea con la pretensión de censurar el contenido del texto propuesto, o bien para formular propuestas alternativas

38 Véase Garcia-Escudero Marquez, P., El procedimiento legislativo ordinario en las Cortes Generales, Madrid, CEPC, 2006, p. 521.

39 Se han manifestado en este sentido, entre otros, Santaolalla Lopez, F., Derecho Parlamentario Español, Madrid, Espasa Universidad, 1990, p. 289. En el mismo sentido se pronuncia, RedONDO GARCIA, A.M., El derecho de Enmienda en los procedimientos legislativas de las Cortes Generales, Madrid, Congreso, 2001, p. 260. 
al mismo. Asimismo la adopción de la modalidad de lectura única redunda en el ejercicio de la función legislativa de la Asamblea. En este sentido, la actividad de la Cámara se limita a someter a un único examen y votación la iniciativa tramitada, por lo que la afectación sobre la facultad de debate y discusión parlamentaria son claras, hasta tal extremo que se ha afirmado, y con razón, que la Cámara se convierte en un mero órgano de ratificación o rechazo ${ }^{40}$.

A este respecto, la jurisprudencia constitucional ha reconocido que las consecuencias que se asocian al procedimiento de lectura única, que tienen que ver con los límites que se introducen en el debate parlamentario, así como en la posibilidad de incorporar enmiendas en el Senado no hurtan automáticamente a las Cámaras las posibilidades de debate posterior, sino que «habrán de analizarse, caso por caso, si se acredita que la adopción de este tipo de procedimiento alteró de algún modo el proceso de formación de la voluntad parlamentaria (STC 204/2011, de 15 de diciembre, FJ 5)» (STC 238/2012, FJ 4). Ahora bien, en relación con la reforma constitucional, creo que no resulta admisible la simultaneidad procedimental con la técnica de lectura única, en la medida en que ello afectaría a las posibilidades reales de participación de la minoría en un debate plural y mermaría su capacidad de enmendar la propuesta de reforma.

En tercer lugar, resulta difícil admitir que una reforma constitucional reúna los elementos de simplicidad de formulación o naturaleza de la propuesta que aconseja el recurso al procedimiento legislativo de lectura única. En esta línea, se ha afirmado que la modificación del artículo 135 CE no respondió a ninguno de los supuestos tasados, ya que «ni su naturaleza lo aconseja, ni su simplicidad lo permite, como sucedió en el caso de la anterior reforma constitucional de 1992 que intercaló el término "y pasivo» en el artículo 13.2 CE y también fue aprobada en lectura única tras previa consulta al TC y su posterior dictamen. En el presente caso, las circunstancias requerían otro procedimiento que permitiera un detenido estudio técnico-jurídico y un debate amplio y reposado» ${ }^{41}$. Sin embargo, a mi juicio, ninguna de estas dos reformas constitucionales tenían cabida entre los supuestos habilitantes del procedimiento de lectura única. En el caso de la primera, fue la concurrencia del consenso sobre la modificación del artículo 13.2 CE lo que justificó la adopción de este procedimiento abreviado. Es cierto que técnicamente se trataba de una modificación muy breve y simple consistente en una mera adición, pero no por ello carecía de relevancia, ni justificaba un cierto debate sosegado ante la opinión pública.

Precisamente, la aprobación de la reforma del artículo 135 creó un mal precedente que puso de manifiesto las consecuencias negativas que, para el desarrollo

40 «La utilización de este procedimiento convierte a la Cámara en un órgano de ratificación o rechazo, restringiendo la capacidad deliberativa que le es propia. De ahí que se presente como un procedimiento especial que, en nuestra opinión, debería ser utilizado excepcionalmente». Véase, Redondo Garcia, A.M., El derecho de enmienda en los procedimientos legislativos de las Cortes Generales, op. cit., p. 260, nota n. ${ }^{\circ} 249$.

41 Consúltese, Carreras, F. de, op. cit., p. 190. 
del debate parlamentario, ocasionó la aplicación simultánea de los procedimientos de urgencia y lectura única junto a la vía procedimental del artículo 167 CE. El acortamiento de los tiempos excluyó la posibilidad de celebrar en sede parlamentaria una discusión sosegada y suficiente sobre el alcance de la reforma proyectada. Como consecuencia de ello, los principios parlamentarios de publicidad, transacción y respeto a las minorías se vieron notablemente afectados, en la medida en que la oposición vio reducidas sus posibilidades de actuación y enmienda en dicho proceso. En esta línea, se ha afirmado que en «democracia la decisión por mayoría es importante, pero más fundamental aún es la preservación de las formas y el respeto a la minoría e incluso a una mayoría que se topó con un acuerdo al que no le quedó más remedio que respaldar, pues careció de tiempo para deliberar y enmendar. El ejercicio de la soberanía popular requiere una liturgia democrática que escenifique un proceso constituyente o revisión constitucional, aunque sea parcial.» ${ }^{42}$

Un cuarto motivo por el que la lectura única resulta una técnica inadecuada para las reformas constitucionales es que esta modalidad procedimental conlleva la supresión de los actos y trámites que se celebran en las Comisiones parlamentarias (y el informe de la Ponencia) durante el proceso de creación de la norma. A este respecto, debe recordarse la importante labor que desempeña la Comisión no sólo en su función dictaminadora de carácter técnico y auxiliar para la Cámara, sino también en su función política como órgano de transacción y negociación política. De esta suerte, su intervención en la fase central del iter legis resulta fundamental para que la Cámara pueda debatir y, en su caso, aprobar la propuesta legislativa. Asimismo, un rasgo que caracteriza la tramitación en esta sede es su carácter informal frente a la rigidez y formalidad inherente al debate y votación en el Pleno. Al tratarse de un órgano más restringido tiene una vocación técnica que permite un mejor desarrollo de los trabajos de la Cámara. De este modo, resulta bastante cuestionable que pueda renunciarse a las facultades dictaminadora y política de la Comisión durante la tramitación de las propuestas de revisión constitucional. Ahora bien, estas consideraciones son aplicables solo para la sustanciación de la modificación constitucional en el Congreso, puesto que las disposiciones del Reglamento del Senado que regulan la tramitación de la reforma constitucional sí que prevén explícitamente la intervención de la Comisión de Constitución con función dictaminadora (art. 154.2 RS).

Por último, a todo lo anteriormente expuesto podría añadirse que un exceso en la celeridad procedimental puede afectar no sólo a la actividad de la Cámara, sino también a los derechos de participación de los parlamentarios. Ahora bien, ello no quiere decir que las técnicas legislativas abreviadas en sí mismas sean inconstitucionales, ni que impidan el ejercicio de las funciones parlamentarias, ni de las facultades de los parlamentarios a tal efecto. Sin embargo, resulta obvio

42 Véase, Bastida, F., op. cit., p. 175. 
que la reducción del tiempo disponible incide directamente en la actividad de los órganos parlamentarios. Sobre este cuestión el Tribunal Constitucional se ha mostrado algo confuso. Así, por lo que respecta a la aplicación del procedimiento de urgencia en el Senado, en la STC 234/2000 sostuvo que la declaración de urgencia por el Gobierno, si bien abrevia el plazo de tramitación, no priva a la Cámara de su función legislativa, al incidir «sobre la cronología del procedimiento pero no sobre el contenido del proyecto». A su juicio, la reducción del tiempo de tramitación no «tiene por qué traducirse en merma alguna de los principios constitucionales que han de informar el procedimiento legislativo en cuanto procedimiento de formación de voluntad del órgano» (STC 234/2000, de 3 de octubre, FJ 13). Por otro lado, la STC 143/2016 extendió esta jurisprudencia sobre el acortamiento de trámites y plazos del procedimiento legislativo a la técnica de lectura única. Sin embargo, en otros pronunciamientos también relacionados con esta misma modalidad abreviada, el Tribunal parece sostener lo contrario al reconocer claramente que se trata de «un procedimiento en el cual resultan notablemente limitadas las posibilidades de participación de las minorías en el proceso de elaboración de la norma» (STC 108/2003, FJ 5).

Pues bien, pese a esta confusa jurisprudencia sobre el acortamiento temporal, creo que la agilización procedimental no está exenta de riesgos, y que un uso incorrecto de las técnicas legislativas abreviadas puede dar lugar a la adopción de decisiones parlamentarias discutidas insuficientemente y puede obstaculizar las negociaciones y los acuerdos necesarios para la formación de la voluntad de la Cámara. Efectivamente, un exceso en la aceleración del procedimiento conlleva ciertas limitaciones sobre los derechos de los parlamentarios y afecta notablemente a algunos de los principios parlamentarios clásicos, como la participación de las minorías en el proceso de adopción de decisiones parlamentarias, especialmente, su capacidad de incidir en la resolución final a través del ejercicio del derecho de enmienda. Por ello, creo que la línea jurisprudencial sostenida en las SSTC 234/2000 y 143/2016 no se puede extrapolar, sin más, a la tramitación parlamentaria de las reformas constitucionales precisamente por los riesgos que podría ocasionar respecto a los mencionados principios parlamentarios y al ius in officium del representante. Como advirtiera Bentham, el fin de la discusión parlamentaria no es la celeridad, por lo que no ha de temerse la demasía en materia de examen, ya que «las malas leyes son únicamente efectos de la precipitación y falta de atención» ${ }^{43}$. En esta misma línea, y como apunta Rubio Llorente, la lentitud es el precio a pagar por una mayor eficacia en el procedimiento de reforma ${ }^{44}$.

43 Véase en Bentrham, J., Tácticas parlamentarias, Madrid, Congreso de los Diputados, 1991, p. 183.

44 En relación con las razones y la conveniencia de tramitar el procedimiento agravado de reforma en dos legislaturas consecutivas, dicho autor afirma que puesto que el poder de reforma es poder constituyente «su configuración constitucional ha de asegurar en la mayor medida posible que la voluntad del órgano que lleva a cabo la reforma coincida con la del pueblo soberano al que ésta se imputa»; y «el precio a pagar por esa mayor eficacia es el de su considerable lentitud. Una lentitud que puede parecer deseable en la mayor parte de 


\section{Las facultades de la Mesa en la selección del procedimiento de reforma aplicable}

A la Mesa de la Cámara corresponde el control de la regularidad de los escritos y documentos de índole parlamentaria en el ejercicio de las facultades de calificación, admisión a trámite y decisión sobre la tramitación de las iniciativas. Por lo que aquí respecta, y para garantizar que las propuestas de reformas constitucionales sean tramitadas conforme al procedimiento constitucionalmente establecido, será necesario que previamente la Mesa califique, admita a trámite y decida sobre su tramitación. Así, en el ejercicio del control de la legalidad parlamentaria en materia de revisión constitucional, al órgano rector le corresponderá examinar la viabilidad procedimental de la propuesta de reforma y fijar el procedimiento aplicable, garantizando un correcto cumplimiento de las normas procedimentales y contribuyendo con ello al perfeccionamiento técnico y la calidad del texto. Precisamente estos tres actos parlamentarios serán determinantes para que la Mesa de curso al cauce procedimental concreto conforme al cual se sustanciará la reforma y, en su caso, si se aplica simultáneamente junto a alguna de las modalidades legislativas abreviadas. Por lo tanto, será primordial conocer el alcance de estas facultades de la Mesa en la selección del procedimiento aplicable.

Asimismo, para garantizar la efectividad de los derechos de los parlamentarios debe llevarse a cabo un correcto desempeño en estos juicios de calificación y admisibilidad. No puede olvidarse que las irregularidades en el desarrollo de estos actos (como puede ser una calificación o inadmisión incorrectas, o la tramitación de la iniciativa por un procedimiento diferente al instado por el autor) pueden lesionar el ius in officium consagrado por el artículo 23.2 CE. Esta idea fue confirmada por el Tribunal Constitucional al sostener que al decidir la Mesa sobre la admisión no puede desconocer que estos actos constituyen una «manifestación del ejercicio de un derecho del parlamentario que los formula, y que, por ello, cualquier rechazo arbitrario o no motivado causará lesión de dicho derecho» (STC 78/2006, FJ 3). Precisamente porque la inadmisión de las iniciativas legislativas puede implicar una limitación del derecho de diputados y senadores a ejercer la función parlamentaria, y con ello, el derecho de los ciudadanos, la jurisprudencia constitucional ha exigido un requisito añadido: la necesidad de la motivación de las decisiones de la Mesa «a fin de tras ellas no se esconda un juicio sobre la oportunidad política» que escaparía por completo a sus potestades (STC 242/2006, FJ 4).

Si bien el alcance de estas facultades varía de unos procedimientos parlamentarios a otros, existe una consolidada doctrina constitucional conforme a la cual la

las ocasiones». Véase, Rubio LloRENTE, «Rigidez y apertura constitucional», La reforma constitucional: ¿ hacia un nuevo pacto constituyente?. Actas de las XIV Jornadas de la Asociación de Letrados del Tribunal Constitucional, Madrid, CEPC, 2009, p. 34. 
calificación y admisión a trámite se efectúa «en función de un canon estrictamente normativo, no político o de oportunidad (que es el que en cambio tiene lugar en el trámite de toma en consideración» (ATC 428/1989, FJ 3). En esta misma línea, el Tribunal ha precisado en reiteradas ocasiones que estos actos no constituyen un juicio de oportunidad política, ya que este tipo de decisiones quedan reservadas al Pleno de la Cámara, no a sus Mesas, que cumplen «la función jurídico-técnica de ordenar y racionalizar el funcionamiento de la Cámaras para su mayor eficiencia, precisamente como tal foro de debate y participación en la cosa pública, precisamente como tal foro de debate y participación en la cosa pública» (STC 208/2003, FJ 4 c).

Por lo que respecta a los juicios de admisibilidad y calificación de iniciativas legislativas, el Tribunal ha admitido que los Reglamentos parlamentarios pueden establecer que la Mesa extienda su examen de las iniciativas más allá de la mera verificación de los requisitos formales, siempre que vengan delimitados materialmente por la Constitución, el bloque de la constitucionalidad o el Reglamento parlamentario. Sin embargo, si la legalidad aplicable no prevé límites materiales a las iniciativas, la verificación en el juicio de admisibilidad debe ser siempre formal. Conforme a la jurisprudencia constitucional, excedería del ámbito de la facultad de las Mesas «calificar y admitir a trámite las iniciativas parlamentarias el control, siquiera liminar, de su constitucionalidad. Lo que no excluye, sin embargo, que el control de las Mesas de las Cámaras, además de verificar el cumplimiento de los requisitos formales reglamentariamente establecidos en cada caso, pueda extenderse a «una verificación liminar de la conformidad a Derecho de la pretensión deducida, junto a un juicio de calificación sobre la idoneidad o procedencia del procedimiento parlamentario elegido» (SSTC 89/2005 y 90/2005 FJ 3, por todas). Ahora bien, tal verificación liminar de la conformidad a Derecho de la iniciativa parlamentaria la hemos circunscrito a aquellos casos en los que la calificación de la iniciativa - y su correspondiente tramitación- se define en atención a criterios de orden material» (ATC 85/2006, FJ 4).

\section{INOBSERVANCIA DE LOS LÍMITES PROCEDIMENTALES EN LA REFORMA CONSTITUCIONAL: VICIO IN PROCEDENDO Y LESIÓN DE UN DERECHO FUNDAMENTAL}

El tema de la justiciabilidad de las infracciones formales y de procedimiento en que pueden incurrir las Cámaras en el ejercicio de su poder reformador, y en concreto, las relacionadas con la selección del procedimiento aplicable por parte de los órganos parlamentarios intervinientes, presenta dos vertientes. Efectivamente, la inobservancia de los límites procedimentales, en general, y del procedimiento adecuado, en particular, puede ser constitutiva de un vicio in procedendo, pero también de una lesión del derecho a ejercer cargo representativo del artículo 23.2 CE en su vertiente del derecho a tramitar las iniciativas 
conforme al procedimiento previsto por las normas constitucionales y el Reglamento parlamentario ${ }^{45}$.

Por lo que respecta a esto último, debe tenerse presente que el Tribunal Constitucional incorporó el denominado derecho al procedimiento $0^{46}$ como contenido del derecho reconocido en el artículo 23.2. CE, al sostener que la participación de los grupos parlamentarios y de los Diputados que lo integran, «en el ejercicio de la función legislativa a través del procedimiento parlamentario reglamentariamente establecido para la concreta iniciativa objeto de tramitación y el desempeño en el mismo de los derechos y facultades que lo acompañan constituye, en principio, una manifestación relevante del ius in officium de representante (en este sentido, STC 118/1999, de 28 de junio, FJ 2). En concreto, puede considerarse que «pertenece al núcleo de su función representativa que los proyectos y proposiciones legislativas, sean en lo que aquí interesan de reforma estatutaria o de reforma constitucional, se tramiten con los requisitos y a través de los procedimientos establecidos en la Constitución española y en el Reglamento del Congreso de los Diputados» ${ }^{47}$ (ATC 85/2006, FJ 6). Como consecuencia de ello, la inobservancia del procedimiento que afecte al núcleo de la función representativa puede vulnerar el ius in officium en su vertiente del derecho a tramitar la reforma constitucional por el procedimiento adecuado. Por ello, y puesto que las decisiones de las Cámaras sobre selección del procedimiento de tramitación de las reformas son actos parlamentarios sin valor de ley, el único mecanismo de impugnación sería el recurso de amparo por la vía del artículo 42 LOTC y por infracción del artículo 23.2 CE.

Desde una segunda perspectiva, en la medida en que la tramitación parlamentaria de la reforma constitucional está sometida a diferentes límites procedimentales que se han ido señalando en este trabajo, la decisión parlamentaria de sustanciar las propuestas de reformas a través de un procedimiento inadecuado podrá dar lugar a un vicio in procedend $0^{48}$. La desviación procedimental puede producirse en el supuesto de la tramitación parlamentaria de las reformas constitucionales de dos modos. De un parte, por inobservancia del procedimiento establecido conforme al criterio material que distingue las vías ordinaria y agravada previstas en los artículos 167 y 168, respectivamente. De otra, por una

45 Respecto al ius in officium, debe precisarse que conforme a la jurisprudencia constitucional «la Constitución no ha asumido en el artículo 23.2 CE un genérico, con la condición de fundamental, al respeto de todos y cada uno de los derechos y facultades del estatuto del parlamentario, sino tan sólo el de aquellos que pudiéramos considerar pertenecientes al núcleo de la función representativa, como son, principalmente, los que tienen relación directa con el ejercicio de las potestades legislativas y de control de la acción de gobierno [SSTC 20/1991, FJ5, y 109/2016, FJ 3 b)]» (STC 139/2017, FJ 4 c).

46 Sobre esta manifestación concreta del ius in officium, consúltese GómEz LuGo, Y., «El derecho a tramitar las iniciativas legislativas por el procedimiento adecuado», INDRET (Revista para el análisis del Derecho), n. ${ }^{\circ} 4,2009$.

47 La cursiva es nuestra.

48 Sobre los tipos de vicios en el procedimiento legislativo, y los diferentes usos de las categorías de vicio formal y vicio procedimentales, véase Biglino Campos, P., Los vicios en el procedimiento legislativo, Madrid, CEC, 1991, p. 101. 
tramitación inadecuada de la iniciativa de reforma cuando los órganos parlamentarios intervinientes deciden sustanciarla simultáneamente por alguno de los procedimientos legislativos abreviados. Además, debe precisarse que este tipo de vicio se produce siempre que se vulnere una norma de procedimiento con independencia de la naturaleza de la disposición infringida, esto es, independientemente de que ésta se ubique en la Constitución o en un Reglamento parlamentario. A este respecto, es doctrina reiterada en nuestra jurisprudencia constitucional que ««[a]unque el art. 28.1 de nuestra Ley Orgánica no menciona los Reglamentos parlamentarios entre aquellas normas cuya infracción puede acarrear la inconstitucionalidad de la Ley, no es dudoso que, tanto por la invulnerabilidad de tales reglas de procedimiento frente a la acción del legislador como, sobre todo, por el carácter instrumental que esas reglas tienen respecto de uno de los valores superiores de nuestro ordenamiento, el del pluralismo político (art. 1.1 CE), la inobservancia de los preceptos que regulan el procedimiento legislativo podría viciar de inconstitucionalidad la ley cuando esa inobservancia altere de modo sustancial el proceso de formación de voluntad en el seno de las Cámaras» [STC 99/1987, de 11 de junio, FJ 1 a)].» (STC 103/2008, FJ 5º).

Teniendo en cuenta que la Constitución carece de cláusulas de intangibilidad, que nuestro sistema de fuentes no reconoce la categoría de ley constitucional o ley de reforma constitucional, y que las normas de producción de la reforma permiten su revisión total, resulta cuestionable admitir un control sobre el contenido de la reforma constitucional, en la medida en que no existe un parámetro material para enjuiciar la constitucionalidad de la misma. A este respecto, Villaverde Menéndez sostiene — muy acertadamente_ - que la ausencia de parámetro imposibilita lógica y jurídicamente el control y la posible declaración de inconstitucionalidad; y para que exista este parámetro es necesaria una relación jerárquica entre la norma controlada y la que sirve de criterio para el juicio de constitucionalidad $^{49}$. No obstante, ello no es óbice para admitir el control formal de las reformas constitucionales, ya que en este supuesto sí contamos con un parámetro de constitucionalidad constituido por las normas de la Constitución y de los Reglamentos parlamentarios que disciplinan los modos de producción legislativa y de la propia reforma constitucional. Asimismo, la posibilidad de controlar la constitucionalidad de los límites procedimentales a la reforma constitucional es una exigencia derivada precisamente de la dualidad de procedimientos previstos para su tramitación parlamentaria.

Llegados a este punto, resulta obligado cuestionarse, aunque sea muy brevemente, por la competencia para controlar la adecuación procedimental de la reforma constitucional, y en su caso, por las vías procesales de impugnación a tal efecto. En cierto modo, esta cuestión ha quedado indirectamente resuelta con

49 Villaverde Menéndez, I., «El control de constitucionalidad de las reformas constitucionales. ¿Un oxímoron constitucional? Comentario al ATC 9/2012», TRC, n. 30, 2012, p. 495. 
motivo del ATC 9/2012, del que se desprende que el Tribunal reconoce implícitamente su competencia para resolver la inobservancia de los límites procedimentales en que pueda incurrir el poder de reforma, si bien desde la óptica de la lesión de los derechos afectados y a través del mecanismo procesal del recurso de amparo parlamentario Aunque ni la Constitución, ni de la LOTC contienen disposición alguna que lo prevea expresamente, la doctrina ha admitido que esta competencia quedaría atribuida al Tribunal Constitucional. En este sentido, Aragón Reyes ha sostenido que dicha competencia no se apoyaría «en una atribución explícita, sino implícita, derivada del carácter mismo de la Constitución (que obliga, jurídicamente, claro está, a todos los poderes públicos, art. 9.1 CE) y de la posición y naturaleza del propio Tribunal Constitucional $»^{50}$. Ahora bien, no puede omitirse que esta intervención del Tribunal Constitucional no está exenta de dificultades y puede resultar especialmente problemática en el supuesto de que la reforma sea ratificada mediante referéndum. En este sentido, coincido con Jiménez Campo cuando afirma que "políticamente la adopción de la revisión constitucional por el cuerpo electoral debe admitirse que sana cualquier irregularidad en el proceso que a aquélla llevó» ${ }^{51}$.

Admitida la existencia de límites procedimentales al poder de reforma, así como la competencia implícita del Tribunal Constitucional para enjuiciar las posibles transgresiones o vicios formales y procedimentales en que pueda incurrir el poder reformador o las Cámaras al tramitarla tramitación de la reforma, quedaría por dilucidar una última cuestión concerniente a los mecanismos de impugnación. A este respecto ni la Constitución, ni la Ley Orgánica del Tribunal Constitucional han previsto procedimientos que permitan enjuiciar la regularidad del procedimiento de reforma. Además, teniendo en cuenta que en nuestro ordenamiento no existe la categoría de ley de reforma constitucional, sería cuestionable la utilización de los instrumentos de control previstos en los artículos 161 (recurso de inconstitucionalidad) y 163 (cuestión de inconstitucionalidad) de la Constitución. Sobre esta cuestión, existe cierto acuerdo doctrinal para proponer el recurso previo de inconstitucionalidad como la opción más adecuada, o al menos, menos problemática, para impugnar la reforma y que podría incorporarse mediante una modificación de la LOTC ${ }^{52}$. En estos supuestos, el parámetro de control vendría constituido por los preceptos de la Constitución y los Reglamentos parlamentarios que ordenan y articulan el proceso de revisión constitucional, y en concreto, los límites procedimentales detallados en

50 Aragon Reyes, M., Estudios de Derecho Constitucional, Madrid, CEPC, 2013, p. 242.

51 Véase Jiménez CAMPo., J., «Algunos problemas de interpretación en trono al Título X de la Constitución», RDP, n. ${ }^{\circ} 7,1980$, p. 102.

52 En este sentido se han pronunciado, entre otros, Aragon Reyes, op. cit., García-Escudero MárQUEZ, P., El procedimiento agravado de la reforma de la Constitución de 1978, Madrid, CEPC, 2007, p. 138. También para el control de constitucionalidad de los límites materiales, se ha sugerido este mecanismo de impugnación; Aláez Corral, B., Los límites materiales a la reforma de la Constitución Española de 1978, Madrid, CEPC, 2000, p. 400. 
este trabajo. Por otro lado, los actos susceptibles de control lo conformarían el conjunto de actos y trámites parlamentarios conducentes a la aprobación de la reforma constitucional — en caso de preverse un control previo - o el acto final que pone fin al procedimiento de revisión constitucional —en caso de articularse un control a posteriori-.

Para finalizar, y a la luz de todas las consideraciones expuestas, sería conveniente que los Reglamentos parlamentarios previeran explícitamente la prohibición de tramitar la reforma constitucional a través de técnicas abreviadas de urgencia y lectura única, como hace el artículo 75.3 CE con respeto a la modalidad de Comisión con competencias legislativa plena. Asimismo, la LOTC debería de establecer un mecanismo procesal para impugnar estos vicios en los procedimientos de reforma constitucional, y reconocer de modo explícito la competencia del Tribunal para resolver dicho proceso constitucional.

$$
* * *
$$

TITLE: The processing of the constitutional reform through abbreviated legislative procedures: a problem of procedural limits

ABstract: Can the Parliament process constitutional reform initiatives applying the procedures of constitutional reform and abbreviated legislative procedures simultaneously? More specifically, can it be considered that the method of single reading and the urgent procedure are adequate for processing the revision of the Constitution? In the decision ATC 9/2012 the Constitutional Court seems to have embraced the thesis of procedural simultaneity, according to which the procedures of constitutional reform could be applied transversally along with the legislative techniques of single reading and urgency. However, making a systematic interpretation of constitutional and parliamentary rules governing the lawmaking process, it might be argued that these kind of abbreviates procedures act as procedural limits in the parliamentary processing of the constitutional revision.

RESUMEN: ¿Pueden las Cámaras tramitar las iniciativas de reforma constitucional aplicando simultáneamente los procedimientos parlamentarios de reforma constitucional y procedimientos legislativos abreviados? Más específicamente, ¿puede considerarse que los métodos de lectura única y urgencia son procedimientos adecuados para tramitar la revisión de la Constitución? En el Auto 9/2012 el Tribunal Constitucional parece haberse decantado por la tesis de la simultaneidad procedimental, conforme a la cual los procedimientos de reforma constitucional podrían aplicarse transversalmente junto a las técnicas procedimentales de lectura única y de urgencia. Sin embargo, baciendo una interpretación sistemática de las normas constitucionales y parlamentarias que regulan el modo de producción legislativa, es posible deducir que dichas modalidades abreviadas actúan como límites procedimentales en la tramitación parlamentaria de la revisión de la Constitución.

KEY WORDS: Procedural limits of the constitutional reform, abbreviated legislative procedures, single reading method, urgent procedure, control of constitutionality of the constitutional reform.

Palabras Clave: límites procedimentales de la reforma constitucional, procedimientos legislativos abreviados, método de lectura única, procedimiento de urgencia, control de constitucionalidad de la reforma constitucional.

FECHA DE RECEPCIÓN: 15.02.2018

FECHA DE ACEPTACIÓN: 05.02.2019 
